University for Business and Technology in Kosovo

UBT Knowledge Center

Oct 28th, 9:00 AM - Oct 30th, 5:00 PM

\title{
The importance of innovative solutions for information flow in a multinational construction project
}

\author{
Blerta Vula Rizvanolli \\ University for Business and Technology, blerta.vula@ubt-uni.net
}

Follow this and additional works at: https://knowledgecenter.ubt-uni.net/conference

Part of the Architecture Commons

\section{Recommended Citation}

Rizvanolli, Blerta Vula, "The importance of innovative solutions for information flow in a multinational construction project" (2016). UBT International Conference. 70.

https://knowledgecenter.ubt-uni.net/conference/2016/all-events/70

This Event is brought to you for free and open access by the Publication and Journals at UBT Knowledge Center. It has been accepted for inclusion in UBT International Conference by an authorized administrator of UBT Knowledge Center. For more information, please contact knowledge.center@ubt-uni.net. 
Book of Proceedings

International Conference on Architecture and Spatial Planning

\title{
THE IMPORTANCE OF INNOVATIVE SOLUTIONS FOR INFORMATION FLOW IN A MULTINATIONAL CONSTRUCTION PROJECT
}

\author{
Blerta Vula Rizvanolli \\ UBT - Higher Education Institution, Lagja Kalabria, 10000 p.n., \\ Prishtine, Kosovo \\ blerta.vula@ubt-uni.net
}

\begin{abstract}
Construction project presents highly complex one-of-a-kind environments which require engagement of many parties for a long time period. Data insertion from different sources should be managed and controlled avoiding conflicts and cost overruns. In addition to efficient and effective material flow, the management of construction projects is the most informationinfluenced industry, which entails timely and accurate communication between parties involved. Nowadays, innovative web-based solutions are applied to insure the inter-organization of the participants' communication. Findings from the literature review have shown online information exchange in construction management to be of great importance. In this paper we present the case study of a real estate international investment in Albania which uses an online platform as a communication and coordination tool between project stakeholders. This followed by recommendations on improving their information flow with the aim of full integration of all parties involved in the project.
\end{abstract}

\section{Introduction}

Construction industry is a dynamic environment due to a highly developed technology, integrated budgets and multi structured processes. Activities in a construction industry generally involve a process of developing, designing, tendering and awarding, constructing, supervising and commissioning. Additionally, the projects internationalization is resulting in increased project management complexity. Chan et al. (2004) have researched the variables influencing construction projects success, concluding that two of the most important components are procurement related factors and human related factors which define the interrelation and communication of the parties involved in the project as designers, managers, client, contractors, subcontractors, consultants, suppliers and manufacturers. Furthermore Blismas et al. (2004) have also concluded that the major factors which influence project delivery are environmental one, client influences, third-party influences and planning influences 


\section{THE IMPORTANCE OF INNOVATIVE SOLUTIONS FOR INFORMATION FLOW IN A MULTINATIONAL CONSTRUCTION PROJECT}

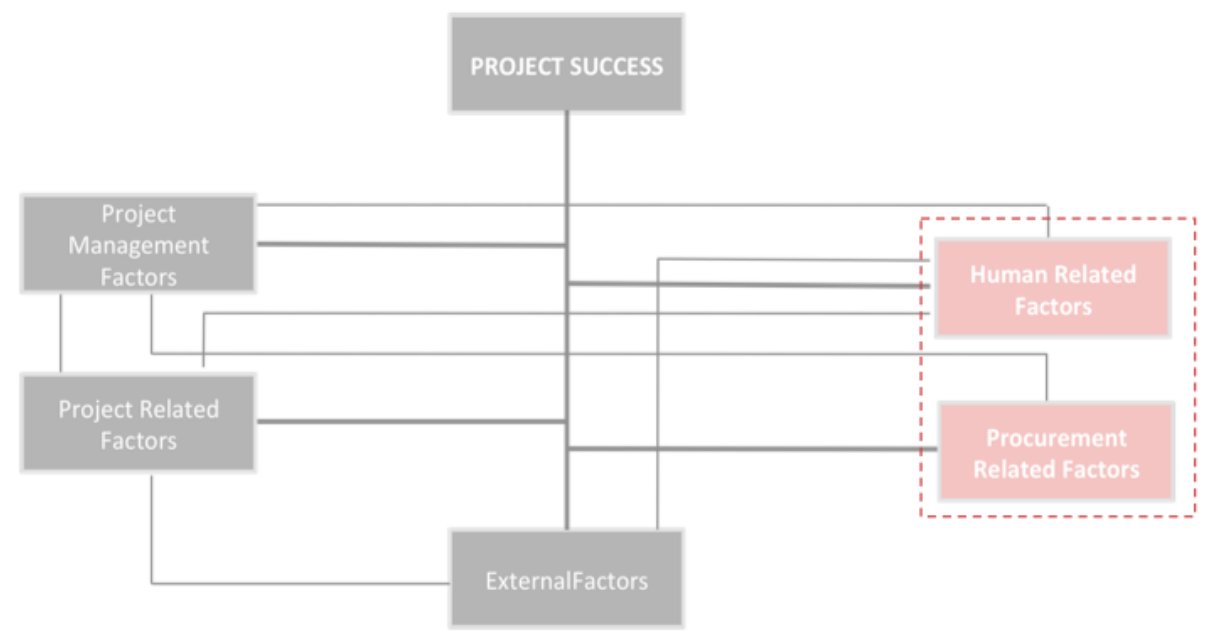

Fig. 1. Conceptual framework for factors affecting construction project success

Vrijhoef and Koskela (2000) have identified four major roles of information flow in construction projects; the first one is Improving the interface between construction site and supply chain, aiming to reduce costs and construction duration; second is to improve the supply chain itself, intending to reduce logistic costs, lead-time and inventories; thirdly to transfer the activities from the construction site to the earlier stages of supply chain trying to decrease the overall costs and project duration; and finally to integrate the supply chain and construction site production. These four roles are applied to increase efficiency and effectiveness of the project.

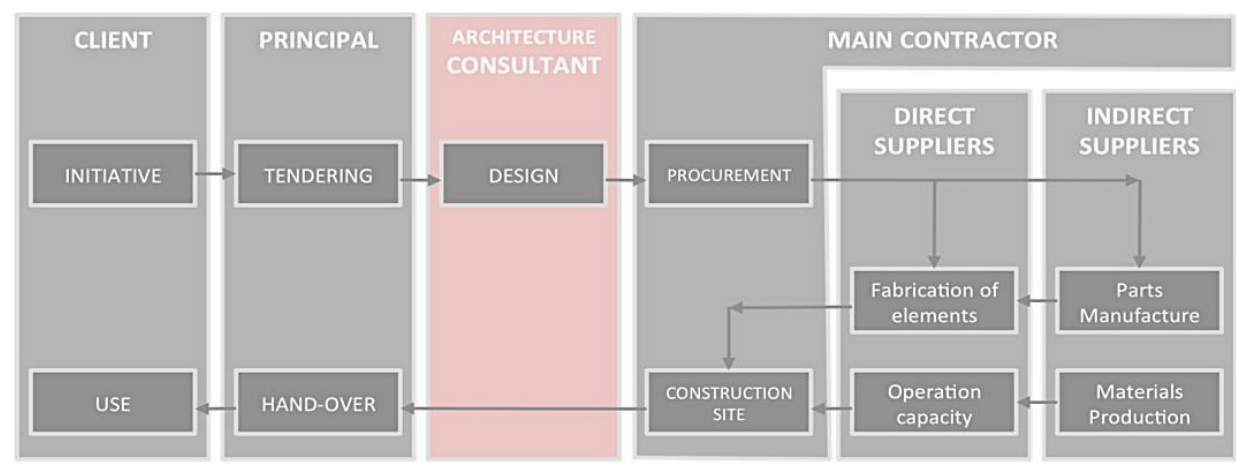

Information Flow (orders, schedules, forecasts, etc. )

Materials Flow (suppliers, production, deliveries, etc. )

Fig. 2. Configuration of a information fow in a construction project

Assaf et al. (1995) have identified the main factors causing the delay of the construction project expressed by contractors, architectural and engineering firms and projects owners. The three parties agree that the preparation and approval of final design (shop-drawings) as well as design changes are the major factor for delaying the projects. 
The goal of this paper is to examine the crucial factor of Information Flow in a multinational environmental construction project and the importance of using the web-based technology in coordination, communication and integration of project participants.

\section{Critical Evaluation of the Literature on Information Flow}

Construction industry is widely known for its highly fragmented structure, slow-moving productivity, high investment costs, time-schedule overrun and conflicts between activities that differs it from any other manufacturing industry. Taking in consideration the number of parties involved in the process and the importance of effective decision-making, has affected the industry to be a subject of a sophisticated Information Flow process.

Xue et al. (2007) and Titus and Bröchner (2005) have defined Construction Information Flow as a communication network of multiple organization and correlation which comprise as the capital flow between the client, designer, contractor and suppliers. It is the most information-influenced industry varying from information which includes drawings and pictures to cost analysis and budget reports, risk analyses, contracts and time schedules. They consider that two-third of organisations problems are caused by inefficient communication of project information. Emmitt and Gorse (2006) also consider that the project success is highly depended by relational and taskbased communication.

\subsection{Information Flow in Multinational Construction Project}

Sophisticated construction projects may require months of planning and exploration. They usually include many organizations and individuals from different sectors and countries asked to work together in an integrated and collaborative environment. According to Dainty et al. (2007) the information flow which circulates in such endeavour is enormous and shall yet be effectively managed. The intention of remaining competitive in globalized market of construction industry while benefiting from the experienced multicultural teams, confronts the managers with fundamental challenge to ensure powerful communication and information paths.

Despite the several efforts to bring construction information flow to the level of manufacturing, according to Briscoe and Dainty (2005), it still endures low-skill, poorly equipped and labourintensive sector. They further identify that the preferred mechanism to deliver value to the client in international environment of construction projects is through partnering, even though this practice is mainly applied between general contractors and bigger suppliers and it is not spread to the second level of sub-contractors and smaller suppliers.

Because of many parties involved and limited level of trust between them, the industry mainly relies on transaction rather than relationships between partners (Dubois and Gadde, 2000). This is not the case of long term partners which follow each other in more than one project and share good sense of communication and information distribution. Briscoe and Dainty (2005) conclude that there are several components impacting the integration of multinational information flow in construction industry as Managing of Communication between general contractors and subcontractors; establishing of a mechanism for fast reaction and problem resolution; utilization of engineering added value in the projects by exploiting the knowledge of multinational professionals involved and alignment of information flow systems between general contractors and its suppliers by establishing long-term relationships.

Well-structured and effective information flow would highly contribute to the outcomes of the international projects, which are processed in the developing countries. Wang et al. (2004) underline the risk that is associated with such projects as difficulties to predict the outcomes the foreseen results can be better or worse than expected or consequences decision making process or planning process. 


\subsection{The importance of Information Flow in Construction Industry}

Project information is assessed as a processed and presented data in a given situation which entitle several actions (Mohamed, 2003). Traditionally the exchange of such data is done on paper based in the form of drawings, calculations, time-schedules, etc. According to Turner and Müller (2003) the challenges of sharing and coordination these data can be distinguished from the construction nature as each project is one-of-a-kind and behaves as a multi-organization or as "temporary multiple-organisation" (Cherns and Bryant, 1984).

Harrison and van Hoek (2008) have highlighted the importance of information flow on integration of supply and demand data which obtain an accurate picture of the business processes and increase its competitive advantage in the market. According to Mangan et al. (2012) out of three key flows which comprise the supply chain - materials, information and resources, information flow is the most complex and multifaceted and is the key to unlock the supply chain responsiveness to demand. While Christopher (2011) has evaluated the importance of the information flow in the supply chain as major transformation of contemporary businesses evaluating that if information is captured and shared upstream then the dependency on inventory reduces.

\subsection{Web-based technology as a main structure of information flow}

The internet is causing a major shift in the way how the information flow in construction is being performed and in overall business culture (Mohamed, 2003) where usage of computer in construction site office was very limited. According to Xue et al. (2007) the benefits of this shift can be revealed by facilitating decision-making, increasing flexibility, transparency, responsiveness and fast reactive operation. They emphasize the significant role of using webbased Information Hub as an information flow system which presents single point information database enabling coordination of all parties involved and maximizing communication transferring efficiency. As specified by Mead (1997) there are four types of construction information which can be shared and processed in a web-based system: Design, Project, Financial Data and Management Data.
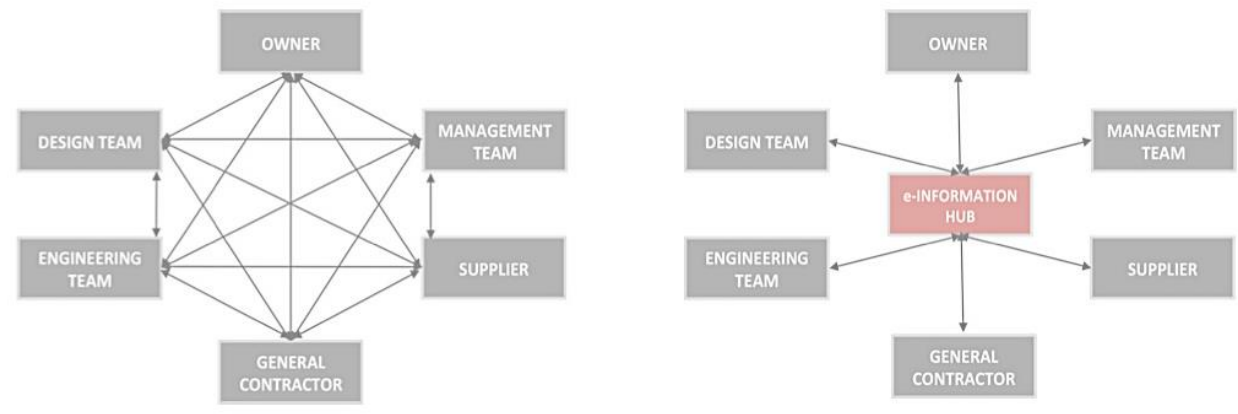

Fig. 3. Communication efficiency in the case of using and not using e-Information Hub

Wang et al. (2007) motivate using e-information hub as a standardized interactions between parties involved in the project, indentifying it as a portal which reduce the probability for errors and exceptionally increase efficiency. This would enable project participants to share and communicate information just by logging in with a specific name and security password. Each 
Book of Proceedings

International Conference on Architecture and Spatial Planning

participant has strictly pre-defined responsibilities which provide him with limited rights of uploading, changing and reviewing the plans and documents in the portal database.

Furthermore (Mohamed, 2003) stressed out the importance of significantly decreased time response to projects requirements due to application of web-based information-hub. It is also beneficiary on decreasing the cost of exchanging the drawings between project participants, which in the traditional way used to be printed in large formats and in multiple copies, one for each participant and if all the number of each drawing revisions is considered, which may exceed few thousands, than the cost of keeping the archives of the printed drawings would be very high. Based on a calculation made by Crotty (1995), approximately 1000 technical documents are produced for each $\quad \$ 1$ million project cost, this way using a web-based platform for communication between the participants of the projects would fundamentally change the interorganisational way of cooperation by reducing costs, lowering risks and increasing trust.

\section{Case Study}

\subsection{Country and Company}

Albania is a country located in South Eastern part of Europe, which is extensively following the trends of using technology-based solutions for complicated projects that comprises many participants. Overall Internet usage in Albania has been increased dramatically over the last years reaching the level of $62.8 \%$ in 2016.
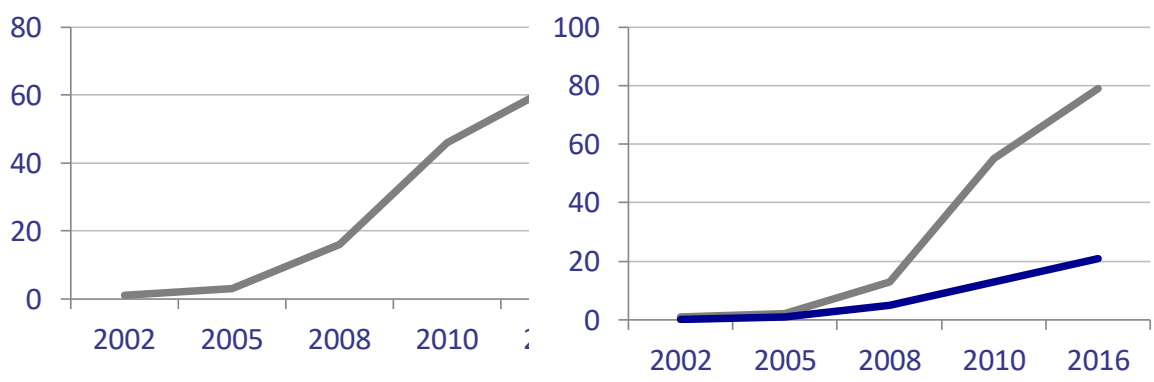

Fig. 4. Internet Usage in Albania 2002 - 2016 Fig. 5. Email usage vs. Online Platforms in construction

Construction industry does not stand behind. In this industry, $79 \%$ of projects use emails to exchange information but only $21 \%$ of projects have adopted special online platforms.

The large real estate project located in Albania is a foreign direct investment of a family owned company based in Germany. The project comprises constructing of 17 office buildings, to be rent to Final Users, with the complete related infrastructure including roads, landscape, water and waste water treatment plants. The project is divided in five construction phases. The preparation stage started in 2008, considering all the necessary designs, plans and permits to start construction which has its ground-break after three years. The general contractor is a Greek company specialized in large and complex construction in the region.

The project communication strategy represents an unusual environment comprising different mindsets of parties involved. German, Albanian and Greek engineering environment show dissimilar working culture and performing standards in the construction industry. Albanians are more focused in progress in the time-frame of construction site, providing fast and not wellplanned solutions during the process which may later cause many problems. While the Germans 


\section{THE IMPORTANCE OF INNOVATIVE SOLUTIONS FOR INFORMATION FLOW IN A MULTINATIONAL CONSTRUCTION PROJECT}

prefer to take time and plan everything in advance, especially taking in consideration all the risk related to investment in developing countries. Greek engineers are experienced with the German attitude of working, but as they are responsible only for the first construction phase and they agreed for lump-sum contract limited to 22 months for construction, on several occasions they support Albanian point of view.

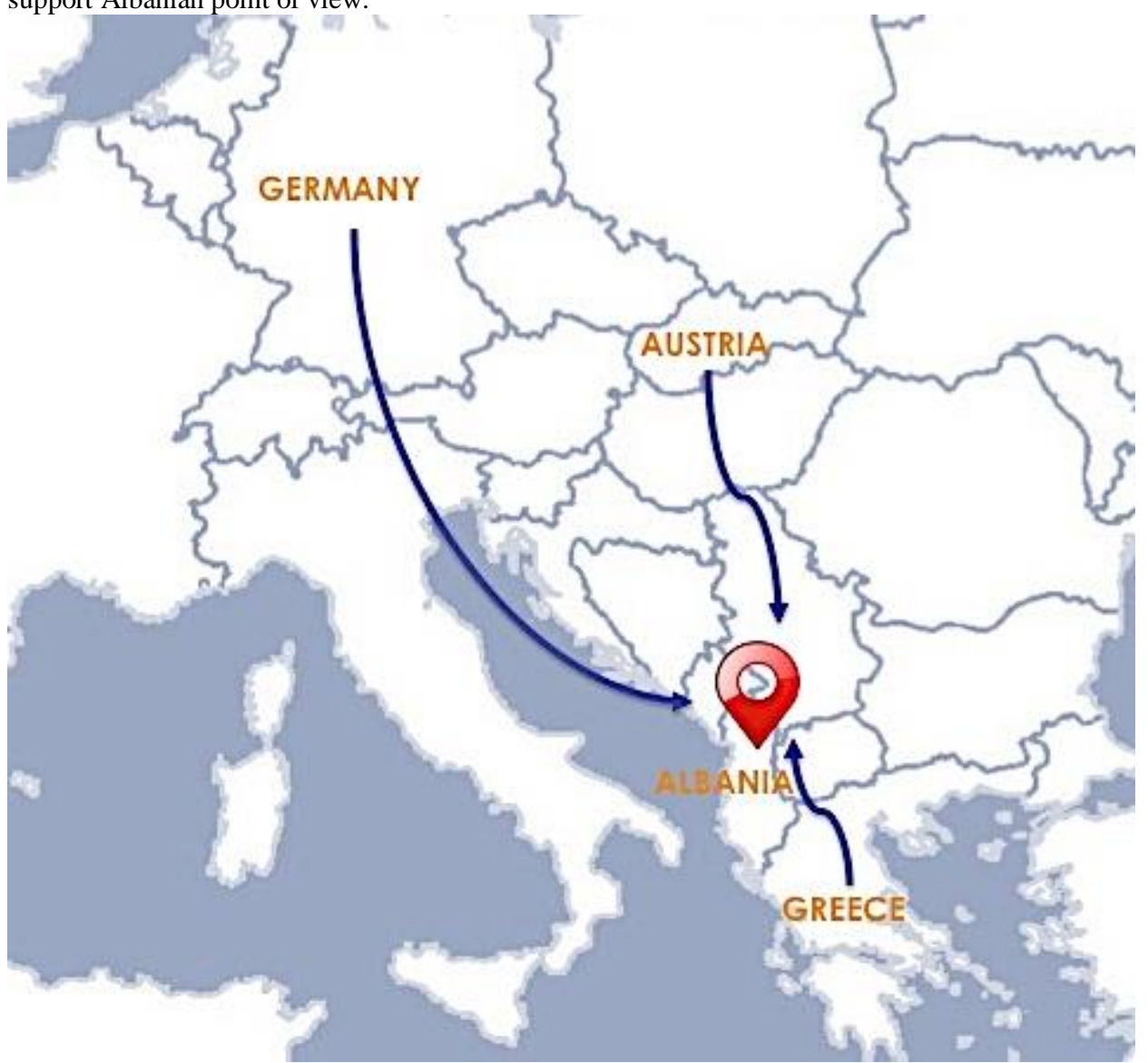

Fig. 6. Project Environment

Responsibilities and authorities were distributed to parties involved in the project. The client as a main decision-maker is located in Germany. Construction company headquarters and engineering staff is located in separate offices in Athens and Thessaloniki. They are responsible for preparing shop-drawings based on the pre-design prepared by the client in the bidding phase. This drawing shall be approved by the client consulting companies before executing them in the construction site. The company responsible to approve architectural drawings is located in Germany. The companies responsible to approve the infrastructure and landscape drawings are located in Austria while the company responsible for electrical drawings is located in Albania. Additionally, supervising company is required by Albanian Construction Law to control and inspect the works. Most of the sub-contractors were located in Albania while the suppliers differ from the region and several European Countries.

\subsection{Communication and Information Flow within the Project}


Book of Proceedings

International Conference on Architecture and Spatial Planning

In order to coordinate, synchronize and control all the upstream and downstream relationships within the project, the client has established a management team which premises are located in the construction site. They shall ensure that the enormous information, which flows between the participants, would be efficiently and cost-effectively processed while it's on time for the construction activities.

The communication language was set to English and all the documents have to comply in a certain standard. The management team was in charge to give answer and solutions to the contractor on behalf of the client, while fulfilling the Final Building Users requirements and at the same time defending Clients interests on the project.

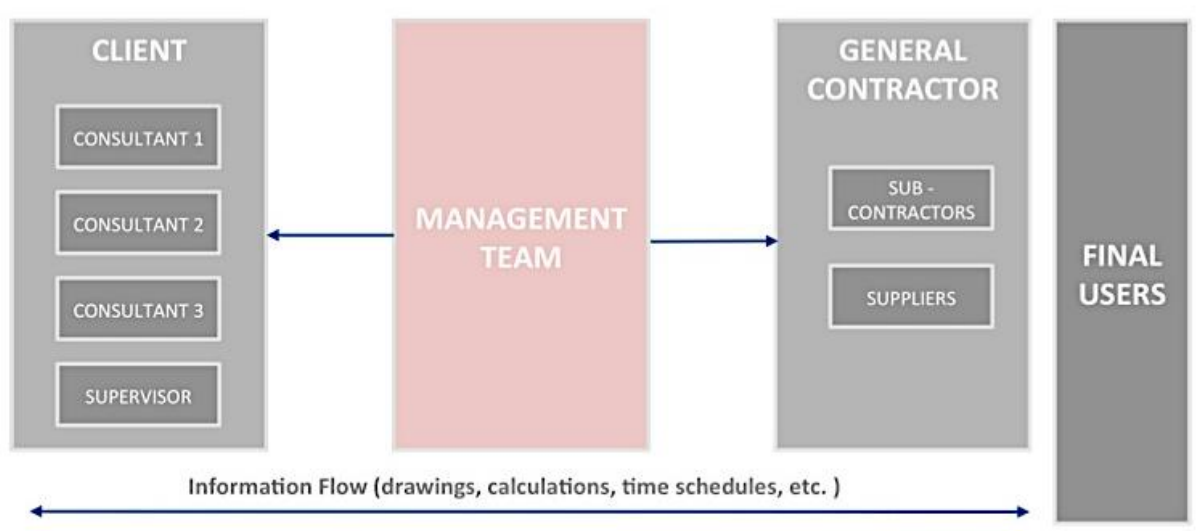

Fig. 7. Information flow of the project

\subsection{Winplan ++ - The Web-based communication platform}

With the intention of managing, coordinating and controlling all engineers, taking in consideration their physical distance and the cost of frequent meetings, as well as considering all the technical documents to be produced for three buildings under construction and the archive space needed to file all of them, the client decided to benefit from the advanced IT technology, using web-based platform as a solution.

Winplan++ online is chosen as a platform which represents an advanced system of managing construction drawings and documents while following the path from creator through the approval process up to the construction site for execution. Separated accounts are created for each team member of Client, Management Team, Consultants, Supervisors and General Contractor which they can access through a unique ID and chosen password which can be changed periodically by the user.

The platform is divided in two main parts, Documents and Drawings. Every team have predefined rights and responsibilities on the way of communicating with the others. Only the client has the rights to check and review all the documents and drawings including all the sensitive financial data, while the others possibility to access the database is limited to their responsibility. The database within the Documents and Drawings is further split into main construction disciplines as Architecture, Structural Analysis, Electricity, Mechanical, IT \& Telecommunication, Road and Infrastructure. For the Documents related to contractual relationships between parties, additional folders Client and General Contractor are created. 


\section{THE IMPORTANCE OF INNOVATIVE SOLUTIONS FOR INFORMATION FLOW IN A MULTINATIONAL CONSTRUCTION PROJECT}

Each discipline like Architecture, Electricity, etc. has a detailed structure with its specific categories of Drawings and Documents making it very easy to understand, use and operate for all platform users.
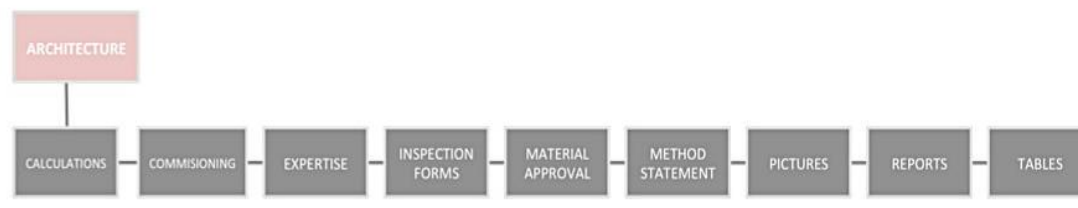

Fig. 8. Architecture - Documents detailed structure

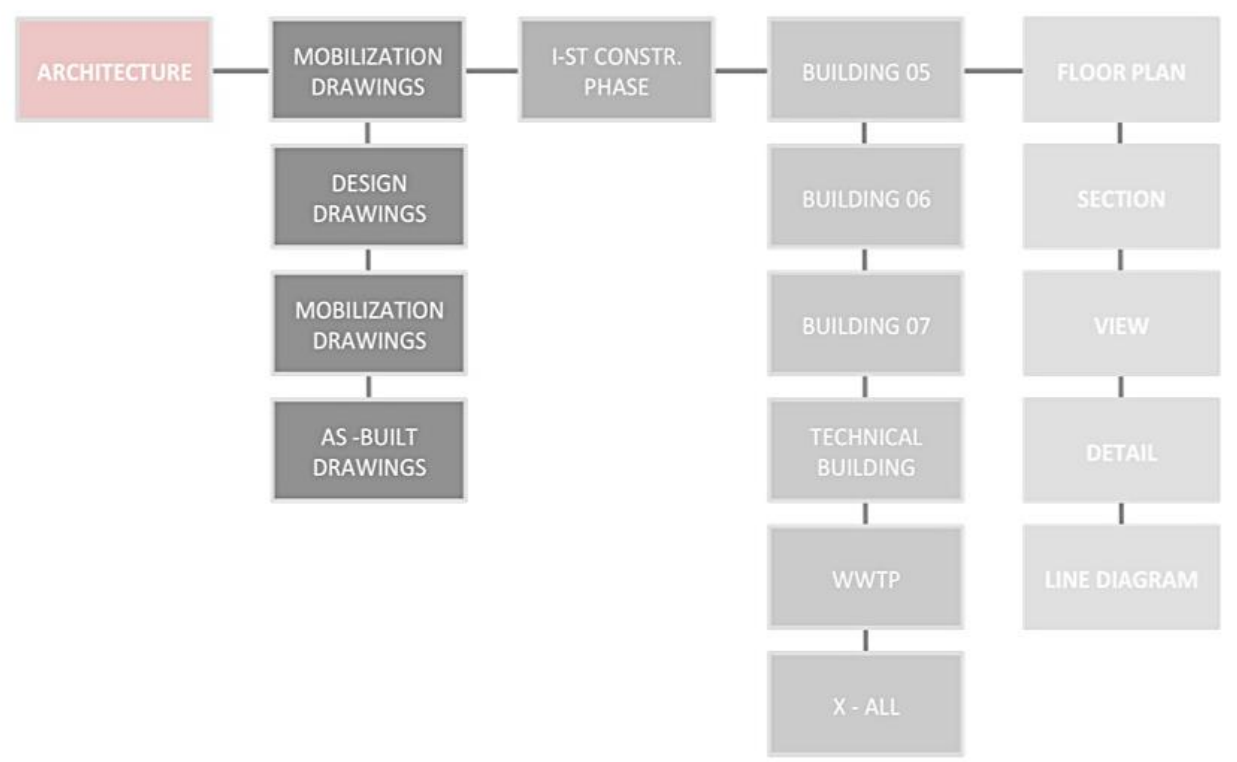

Fig. 9. Architecture - Drawings detailed structure

Comprehensive File-Name Structure for each Document or Drawing is presented and the platform supports only Documents and Drawings which adhere to this structure otherwise it doesn't allow uploading of the file. It is impossible to upload an Architecture Drawing in to Electricity Discipline or vice-versa. This way most of the errors are automatically avoided. 
Book of Proceedings

International Conference on Architecture and Spatial Planning

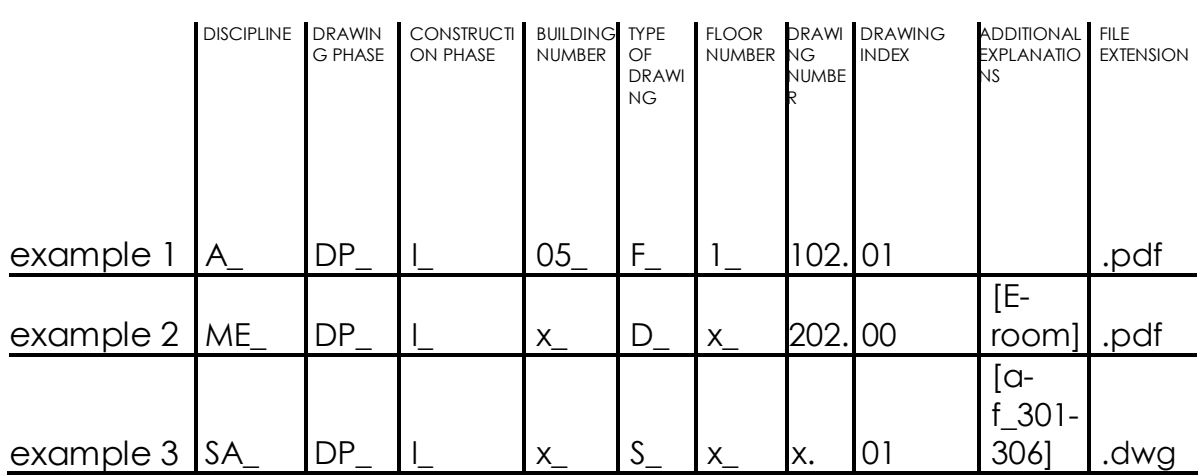

Fig. 10. File-Name Structure

The participants of the platform are assigned with different responsibilities according to their role in the project and for every particular action which is undertaken, like adding, updating or changing a Drawing or Document platform workflow triggers notification activities for the participants assigned by the structure for e.g. if the General Contractor upload a drawing, the Management Team, Client, Consultants and Supervisor are notified by email. The system gives the Consultants 10 working days to answer.

The status that the Consultant may award to that Drawing is Approved - the drawing can be dispatched to the construction site for execution, Approved Under Condition - the drawing can be dispatched to the construction site for execution but needs further technical correction for final approval, Back for Revision - the drawing is not approved and shall be revised and Invalid - the file is not correctly uploaded and can't be used. At the same time that the file is being checked by Consultants, it is also reviewed by the Supervisor who has 5 working days to clarify if the file is according to the country's laws and regulations. Finally the Approved plan are printed and sent to the construction site for execution. 


\section{THE IMPORTANCE OF INNOVATIVE SOLUTIONS FOR INFORMATION FLOW IN A MULTINATIONAL CONSTRUCTION PROJECT}

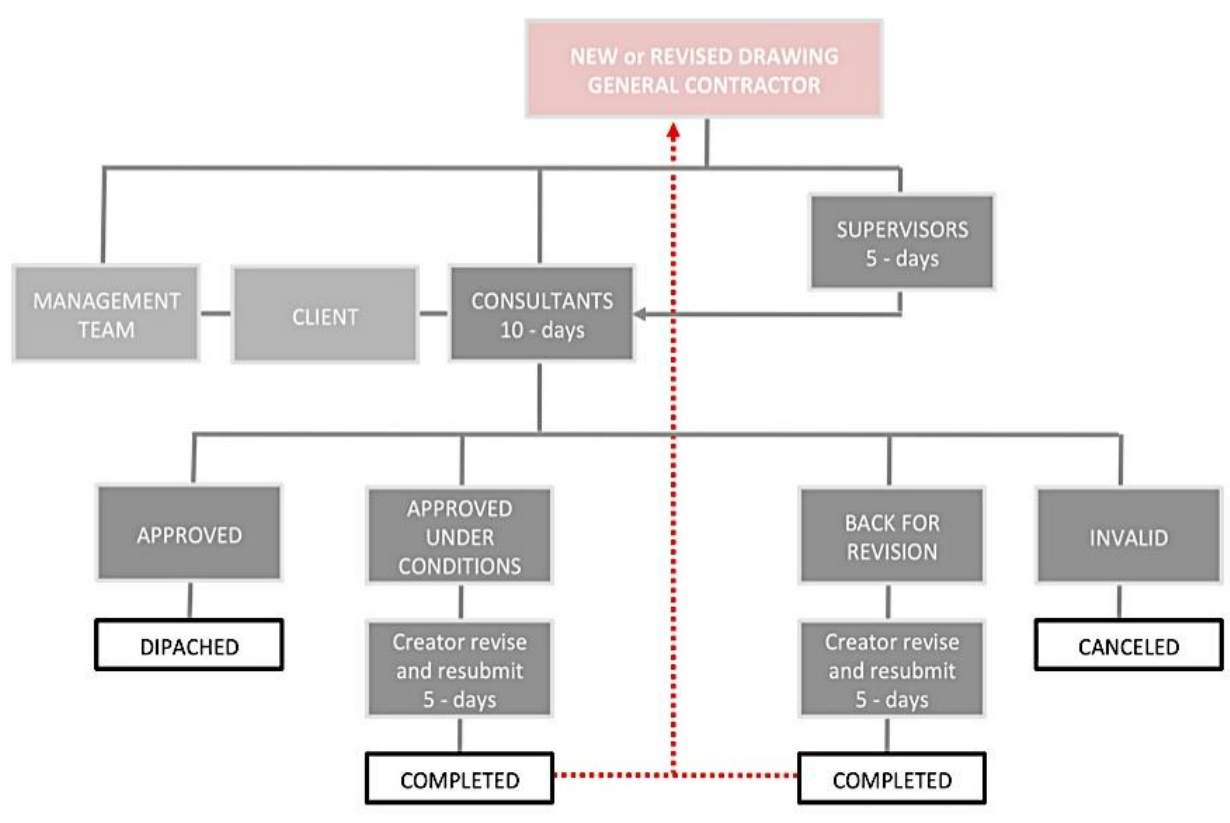

Fig. 11. Information flow and responsibilities of project participants

For every single Drawing and Document a workflow is created where each participant can monitor and control if the file is well-received, when it is opened, by whom it is reviewed or revised. This platform enables full transparency, enforces trust between participants, reduce the costs of communications and meetings as well as filing and archiving and empower an efficient time usage in the project.

\subsection{Improvement opportunities}

As explained above the web-based platform Winplan++ is used to manage the information flow in a construction project. Even that the system is well-functioning and caused no delay on Drawings and Documents dispatching, there is enough room for improvements.

With the intention to achieve accurate information flow effect, Sub-Contractors and Suppliers must be integrated in the platform. According to Briscoe and Dainty (2005) commitment to trustful relationships between General Contractors and Sub-Contractors' would highly contribute to the project communication success. Based on the actual lump-sum agreement, General Contractor is fully responsible for communication and coordination with Sub-Contractors and Suppliers, meaning that the communication may go back to the traditional form of printed documents and physical meetings or it needs additional online platform which enable this communication. This may cause delays and misleading of information, even more it increase the project costs. By including Sub-Contractors and Suppliers in Winplan++, the need for regeneration or re-entering the same information is eliminated insuring data consistency, just in time communication, full transparency and reduction of additional costs. In that Winplan++ would fully integrate the participants serving as a single information-hub and its added value would be further increased from managing and controlling just the information flow, to managing and controlling of materials flow. 
Another valuable recommendation to the project is using of Radio Frequency Identification RFID technology in managing the information flow between offices and construction site where usually a time space gap exist reducing the efficiency and creating confusion. RFID technology enables automatic identification of solutions and data acquisition which in recent years have become very popular in many industries. As shown above, the final approved plans are printed and dispatched to the construction site for execution. In this case they will be substituted with the personal digital assistants which would receive the data through RFID technology. According to Wang et al. (2007) the combination of radio frequency identification technology, personal digital assistants and web-based platform would facilitate full information integration in the project by improving the on-site efficiency and effectiveness.

\section{Conclusion}

The construction industry as a high fragmented one, driven by increased global competition is following the practice of other industries for e-solutions due to increased information availability and complex relationships and responsibilities of the parties in charge. Coordination and integration of information flow is a key issue of construction project management. It requires common business objectives while indicating trust and partnership.

The paper has elaborated the significant role of web-based platform used as a single hub of information flow in a multinational construction project in Albania. The parties responsible for different process of the project are dispersed between Germany, Austria, Greece and Albania challenging the physical ability for communication. The amount of information to be exchanged is enormous including drawings and their revisions, financial calculations data sheets, timeschedules, reports, tests and inspection forms, commissioning, expertise, material approvals, agendas, minutes of meetings and pictures. Deadlines and obligation are automatically assigned and controlled insuring smooth information flow and avoiding delays by tremendous cost reduction of paper production, archiving and transmitting.

Usable and easy to implement recommendations are proposed to attain full integration of the information flow process increasing the added value of the innovative technology based solutions.

\section{References}

1. Assaf, S. A., et al. (1995) Causes of delay in large building construction projects. Journal of management in engineering, 11(2), p. 45-50.

2. Blismas, N. et al. (2004) Factors influencing project delivery within construction clients' multi-project environments. Engineering, Construction and Architectural Management,11(2), p. 113-125.

3. Briscoe, G. and Dainty, A. (2005) Construction supply chain integration: an elusive goal? Supply chain management: an international journal, 10(4), p. 319-326.

4. Chan, A. et al. (2004) Factors affecting the success of a construction project. Journal of construction engineering and management, 130(1), p. 153-155.

5. Cherns, A. B. and Bryant, D. T. (1984) Studying the client's role in construction management. Construction management and economics, 2(2), p. 177-184. 


\section{THE IMPORTANCE OF INNOVATIVE SOLUTIONS FOR INFORMATION FLOW IN A MULTINATIONAL CONSTRUCTION PROJECT}

6. Christopher, M. (2011) Logistics \& supply chain management. Pearson Education Limited.

7. Crotty, R. (1995) Advances Communications in Construction-Broadband Communication in Construction. Bovis Construction, London.

8. Dainty, A., et al. (2007) Communication in construction: Theory and practice. Taylor \& Francis.

9. Dubois, A. and Gadde, L. E. (2000) Supply strategy and network effects—purchasing behaviour in the construction industry. European Journal of Purchasing \& Supply Management, 6(3), p. 207-215.

10. Emmitt, S. and Gorse, C. (2006) Communication in construction teams. Taylor \& Francis.

11. Harrison, A., and van Hoek, R. (2008) Logistics management and strategy. Pearson Education Limited.

12. Mangan et al. (2012) Global logistics and supply chain management. John Wiley \& Sons ltd.

13. Mead, S. P. (1997) Project-specific intranets for construction teams. Project Management Institute.

14. Mohamed, S. (2003) Web-based technology in support of construction supply chain networks. Work Study, 52(1), p. 13-19.

15. Titus, S., and Bröchner, J. (2005) Managing information flow in construction supply chains. Construction innovation, 5(2), p. 71-82.

16. Turner, J. R., and Müller, R. (2003) On the nature of the project as a temporary organization. International Journal of Project Management, 21(1), p. 1-8.

17. Vrijhoef, R. and Koskela, L. (2000) The four roles of supply chain management in construction. European journal of purchasing \& supply management, 6(3), p. 169-178.

18. Wang, L. C., et al. (2007) Dynamic mobile RFID-based supply chain control and management system in construction. Advanced Engineering Informatics, 21(4), p. 377 390.

19. Wang, S. Q., et al. (2004) Risk management framework for construction projects in developing countries. Construction Management and Economics, 22(3), p. 237-252.

20. Xue, X., et al. (2007) Coordination mechanisms for construction supply chain management in the Internet environment. International Journal of project management, 25(2), p. 150-157. 